\title{
AOtR
}

Selected Papers of \#AolR2021:

The 22nd Annual Conference of the

Association of Internet Researchers

Virtual Event / 13-16 Oct 2021

\section{DECOUPLING AS RHETORICAL STRATEGY IN GOOGLE'S GREEN DISCOURSE}

\author{
Rianne Riemens \\ Radboud University, The Netherlands
}

\section{Framing the Climate Crisis}

This paper analyzes the role of tech companies in public debates on the climate crisis. More specifically, it examines Google's corporate environmental discourse (2019-2021) in relation to the ecomodernist movement and its Ecomodernist Manifesto (Asafu-Adjaye et al., 2015). Recent debates on the climate crisis have made the immense energy use of digital platforms an uncomfortable truth for the tech companies that own them. Tech companies have therefore taken a more explicit position as actors in the 'fight' against the climate crisis. By foregrounding technological innovation as a necessity to deal with the climate crisis, they approach it as the ultimate business opportunity (Taffel, 2018). I will answer the question: how does Google frame the relation between technology and nature in its 'tech-on-climate' discourse?

In discourses that frame the climate crisis as business opportunity, the notion of decoupling plays a central role. In An Ecomodernist Manifesto, "decoupling humankind's material needs from nature" is presented as the way to solve the climate crisis (AsafuAdjaye et al., 2015, p. 26). Similarly, Google uses the term decoupling in its 2020 Environmental Report stating its mission to "decouple our business growth from the growth of material use and carbon intensity" (p. 12). ${ }^{1}$ Decoupling thus signifies a separation between human and natural wellbeing, but I argue that it also represents a rhetorical framing strategy in which positive connections between technology and nature are highlighted and uneasy connections obscured. In this paper, I argue that decoupling is used by Google to positively narrativize the relation between nature, technology and humanity.

\section{Platforms as Hungry Machines}

This analysis situates itself in the critical study of the platform society (Van Dijck, Poell \& De Waal, 2018). Platforms exist of separate online services that are interconnected and form part of a larger, continuously expanding platform ecosystem that shapes societies. The dominant economic model of this ecosystem is platform capitalism, in which value is mainly created by monetizing new services and extracting and selling user data (Srnicek, 2017). A small number of platforms play a key role in this ecosystem, that Bratton refers to as 'The Stack': a layered megastructure that functions as "a new architecture for how we

\footnotetext{
1 See https://www.gstatic.com/gumdrop/sustainability/google-2020-environmental-report.pdf 
divide up the world into sovereign spaces" (2015, p. xviii). Despite its connotation to virtuality, this megastructure is "a hungry machine" that relies on an Earth layer to fuel it with energy and raw materials (Bratton, 2015, p. 82). Couldry and Mejias (2019) refer to these extractive practices as "data colonialism," to highlight the continuation as well as expansion of historical processes of appropriation and exploitation.

Regarding the climate crisis, tech companies propose solutions that present a greener, better version of capitalism and simultaneously provide moral legitimacy to their business model (Goldstein, 2018). My hypothesis is that Google's statement to 'decouple' material impact from the wellbeing of the planet is a way to legitimate its business. However, as Taffel (2018, p. 177) argues, tech discourses show an "alarming gap between rhetoric and material reality" and fail "to acknowledge scarcities that constrain the immaterialist fantasy of abundance". Similarly, Crist (2015) critiques the vague conceptualization of nature in the Manifesto and the term decoupling as it obscures an unequal power dynamic of domination over nonhuman life. Because it is unlikely that decoupling is a feasible strategy to deal with the climate crisis (Parrique et al., 2019) and diverts attention from the potentials of degrowth (D'Alisa et al., 2015), it requires careful scrutiny.

\section{Methodology}

While Goldstein (2018) has already observed the ecomodernist tendencies in green entrepreneurship, the environmental approach of platforms is scarcely studied. I will perform an analysis of a selection of Google's publications: two recent sustainability reports $(2019,2020)^{2}$, a video on Google's sustainability mission $(2020)^{3}$, the online data center photo gallery ${ }^{4}$ and the online tool 'Your Plan, Your Planet'5. The approach is a combination of a visual (photos, icons, graphics, lay-out) and textual analysis (titles, main text, captions) (Greenwood et al., 2019). While presented as objective reports, these texts are political documents, designed to create a positive, emotional response among readers (David, 2001). A rhetorical analysis therefore helps to understand how Google's texts create a certain cultural myth of green innovation.

My study of the rhetorical strategy of decoupling builds on Goldstein's (2018) use of the rhetorical trope divisio. This trope helps to separate favored views from opposing or undesired views, allowing for example to strategically balance the wish to save the planet and the wish to create a fortune. I add that decoupling, as example of divisio, reflects the rhetoric function of visuals and text to direct the connections readers make, in this case between Google and the climate crisis (Greenwood et al., 2019). Decoupling as strategy is visible in how romanticized images of unspoiled nature and solar and wind farms, positive figures and claims to save the planet create a positive, curated image of Google's business and its relation to nature, while negative consequences remain largely invisible and environmental responsibility is only partially acknowledged. The strategy of decoupling helps Google to construct the attractive, ecomodernist narrative in which a love for nature goes hand in hand with economic growth.

\section{Conclusion}

This paper presents an analysis of how the rhetorical strategy of decoupling is used in Google's discourse to create a narrative of green growth as the only logical way for

\footnotetext{
2 See https://sustainability.google/reports/

3 Google's Third Decade of Climate Change, 19 Nov 2020, https://www.youtube.com/watch? $\mathrm{v}=\mathrm{sNPas} 3 \mathrm{AY}$ tqw $\& \mathrm{t}=23 \mathrm{~s} \& \mathrm{ab}$

4 See https://www.google.com/about/datacenters/gallery/

5 See https://yourplanyourplanet.sustainability.google/
} 
humanity to move forward. While technological developments might help to decrease the global use of raw materials and fossil fuels, it is important to critically study what promises of independency are made. Through decoupling, Google is able to present its wish to save 'nature' without discussing its use of nature, thus legitimating green platform capitalism. While the narrative of green growth might be attractive, it conflicts with resolutions that centralize degrowth as answer to the climate crisis.

\section{References}

Asafu-Adjaye, J., et al. (2015). An Ecomodernist Manifesto. Retrieved from http:// www.ecomodernism.org/manifesto-english.

Bratton, B. H. (2015). The Stack: On Software and Sovereignty. Cambridge: The MIT Press.

Couldry, N., \& Mejias, U. A. (2019). The Costs of Connection: How Data is Colonizing Human Life and Appropriating it for Capitalism. Stanford: Stanford University Press.

Crist, E. (2015). The Reaches of Freedom: A Response to An Ecomodernist Manifesto. Environmental Humanities, 7, 245-254.

D’Alisa, G., Demaria, F., \& Kallis, G. (2015). Degrowth: A Vocabulary for a New Era. New York: Routledge.

David, C. (2001). Mythmaking in Annual Reports. Journal of Business and Technical Communication, 15(2), 195-222.

Goldstein, J. (2018). Planetary Improvement: Cleantech Entrepreneurship and the Contradictions of Green Capitalism. Cambridge: The MIT Press.

Greenwood, M., Jack, G., \& Haylock, B. (2019). Toward a Methodology for Analyzing Visual Rhetoric in Corporate Reports. Organizational Research Methods, 22(3), 798-827.

Parrique, T., et al. (2019). Decoupling debunked. Evidence and arguments against green growth as a sole strategy for sustainability. Brussels: European Environment Bureau.

Srnicek, N. (2017). Platform Capitalism. Cambridge: Polity.

Taffel, S. (2018). Hopeful Extinctions? Tesla, Technological Solutionism and the Anthropocene. Culture Unbound, 10(2), 163-184.

Van Dijck, J., Poell, T., \& De Waal, M. (2018). The Platform Society: Public Values in a Connective World. Oxford: Oxford University Press. 